\section{ACKNOWLEDGEMENTS}

The authors were supported by the NSW Injury Risk Management Research Centre, with core funding provided by the NSW Department of Health, the NSW Roads and Traffic Authority and the Motor Accidents Authority.

The authors wish to thank the Centre for Epidemiology and Research at the NSW Department of Health for providing the data from the Health Outcomes and Information Statistical Toolkit (HOIST) analysed in this study.

\section{REFERENCES}

1. World Health Organization. International classification of diseases (ICD-10), 10th revision. Geneva: WHO, 1992.

2. World Health Organization. World report on violence and health. Geneva: WHO, 2002.

3. World Health Assembly. Prevention of violence: public health priority. (Resolution no. WHA 49.25). Geneva: WHO, 1996.

4. Potter-Forbes M, Aisbett C. Injury costs! A validation of the burden of injury in NSW, 1998-99. Sydney: NSW Injury Risk Management Research Centre, 2003.
5. World Health Organization. The economic dimensions of interpersonal violence. Geneva: WHO, 2004.

6. Population Health Division, NSW Department of Health. The health of the people of NSW. Report of the Chief Health Officer 2004. Sydney: NSW Department of Health, 2004.

7. SAS Institute. SAS: statistical software, version 8.02. Cary, North Carolina: SAS Institute, 2000.

8. Dobson A, Kuulasmaa K, Eberle E, Schere J. Confidence intervals for weighted sums of Poisson parameters. Stat Med 1991;10: 457-762.

9. Armitage P, Berry G, Matthews J. Statistical methods in medical research. Fourth Edition. Cornwell: Blackwell Science, 2002.

10. Hayen A, Mitchell R. NSW injury profile: A review of injury hospitalisations during 1989-90 to 2003-04. Sydney: NSW Injury Risk Management Research Centre; 2006.

11. Hawkins J, Herrenkohl T, Farrington D, Brewer D, Catalano $\mathrm{R}$, Harachi T, et al. Predictors of youth violence. Juvenile Justice Bulletin April 2000:1-12.

12. Schmertmann M, Finch C. A demographic profile of deaths due to interpersonal violence in New South Wales. $N S W$ Public Health Bull 2006; 17(1-2):4-7 娚

\title{
DRUG-RELATED AGGRESSION AMONG INJECTING DRUG USERS
}

\author{
Emma Black and Louisa Degenhardt \\ National Drug and Alcohol Research Centre \\ University of New South Wales
}

Recent years have seen the diversification of the methamphetamine markets in Australia, with increased availability and the use of more potent forms of methamphetamine such as ice/crystal and base methamphetamine. ${ }^{1}$ Intoxication due to the use of stimulants such as methamphetamine has been associated with aggressive and violent behaviour. The connection is not a direct causal relationship, but is thought to be influenced by a number of other factors such as individual, situational and cultural factors. ${ }^{2,3,4,5}$

As a consequence of these changes to the methamphetamine market, there has been understandable concern that there could also be a concomitant increase in aggressive behaviour among those using the drug.

An association between alcohol and aggression is established ${ }^{2,3}$, although a range of other factors, such as context, pharmacology and individual differences, also play a role. ${ }^{3,6,7}$ Evidence supporting a link between benzodiazepines and aggression is less conclusive. However, as with alcohol, a wide range of variables including age, genetics, mood, environment and personality characteristics, such as poor impulse control, have been implicated in modifying individual responses. ${ }^{8,3}$

This article examines associations between self-reported aggressive behaviour and substance use among an Australia-wide sample of injecting drug users (IDU), where substance-related aggression was defined as aggression while being either under the influence of a drug or during withdrawal.

\section{METHODS}

The study utilised the cross sectional survey component of the Illicit Drug Reporting System (IDRS), an annual survey of IDU in metropolitan Australia.

Participants were injecting drug users $(n=948)$ recruited in key drug market areas in capital cities in all Australian jurisdictions. To be eligible, participants had to have been injecting at least monthly during the six months preceding the interview and have lived for at least 12 months in the capital city in which they were interviewed. Data are presented here from 2004. The number of participants from each state or territory were: NSW 157, Victoria 150, Northern Territory 111, Queensland 129, Australian Capital Territory 100, South Australia 101, Tasmania 100, and 


\section{TABLE 1}

\section{DEMOGRAPHIC CHARACTERISTICS OF THE INJECTING DRUG USER SAMPLE, $(\mathrm{N}=948)$, AUSTRALIA, 2004}

\begin{tabular}{|lc|}
\hline Characteristic & $\%$ \\
\hline Male & 66 \\
English-speaking background & 95 \\
Aboriginal or Torres Strait Islander* & 10 \\
Employment: & \\
Unemployed / on income support & 77 \\
Full-time employment & 10 \\
Part-time / casual employment & 5 \\
Student & 2 \\
Home duties & 6 \\
Prison history & 46 \\
Currently in drug treatment & 30 \\
Methadone & 12 \\
Buprenorphine & 4 \\
Other & \\
Not currently in treatment & 54 \\
\hline Source: Illicit Drug Reporting System \\
* Percentage reflects all jurisdictions except NSW, where data \\
$\quad$ were not collected in 2004. \\
† Includes, but is not restricted to, counselling, naltrexone, de- \\
$\quad$ tox, therapeutic community and Narcotics Anonymous. \\
\hline
\end{tabular}

Western Australia 100. Each jurisdiction aims to recruit 100 participants each year, with the exception of NSW and Victoria, where 150 are recruited.

The IDRS IDU survey contains questions on a number of areas including: demographic information; drug use history; the price, perceived purity and availability of illicit drugs; criminal activity; injecting risk behaviours; health; and general drug trends. In 2004, in response to concerns raised about substance-related aggression, the following self-report items were included: 'In the last six months have you become verbally aggressive [threatening, shouting, abusive] following the use of alcohol and/or any other drug?' and 'In the last six months have you become physically aggressive [shoving, hitting, fighting] following use of alcohol and/or any other drug?' Questions were worded in such a way that participants might interpret them as referring to while they were under the influence of a drug, while experiencing withdrawal, or both. The questions could be answered by referring to incident(s) in which one or both forms of aggression (verbal/physical) were experienced. Multiple drugs could be nominated, referring to one or more occasions of aggression. However, it was not possible to identify particular combinations of drugs that may have been implicated.

IDU were interviewed between June and August of each year. Interviews took approximately 30 to 50 minutes to complete. The method of recruitment has remained consistent across years and jurisdictions, and further details are available elsewhere. ${ }^{9}$

Data were analysed using SPSS for Windows, Release 13.0 (2004). Statistical tests were two tailed using a 5 per cent level of significance. Categorical variables were analysed using a multivariate logistic regression and odds ratios with 95 per cent confidence intervals were calculated.

\section{RESULTS}

\section{Demographics}

The majority of the sample were male, from an Englishspeaking background, and with a mean age of 33 years (see Table 1). The IDRS sample in general represents a marginalised group, with large numbers of participants reporting that they were unemployed or receiving income support (77 per cent), had significant prison histories and were poorly educated (with a mean of 10 years of education,

\section{TABLE 2}

FREQUENCY OF DRUG USE* IN THE PAST SIX MONTHS AMONG INJECTING DRUG USERS, BY DRUG, AUSTRALIA $2004(\mathrm{~N}=948)$

\begin{tabular}{|c|c|c|c|c|}
\hline \multirow[t]{2}{*}{ Drug } & \multicolumn{2}{|c|}{$\begin{array}{l}\text { Injecting drug users reporting use } \\
\text { in the past } 6 \text { months }\end{array}$} & \multicolumn{2}{|c|}{$\begin{array}{c}\text { Median number of days used in the past } 6 \\
\text { months among those reporting use } \\
\text { in the past } 6 \text { months }\end{array}$} \\
\hline & $\mathrm{n}$ & $\%$ & & \\
\hline Heroin & 657 & 69 & 72 & (3 days/week) \\
\hline Benzodiazepines & 633 & 67 & 30 & (1-2 days/week) \\
\hline Alcohol & 645 & 68 & 12 & (once per fortnight) \\
\hline Speed (powder form) & 501 & 53 & 9 & \\
\hline Base & 357 & 38 & 10 & \\
\hline Ice & 488 & 52 & 6 & \\
\hline Methamphetamine (any form) $\dagger$ & 689 & 74 & 22 & (once per week) \\
\hline \multicolumn{5}{|c|}{ Source: Illicit Drug Reporting System } \\
\hline \multicolumn{5}{|c|}{ * ' Use' refers to any of the following: injection, inhalation, ingestion and/or intranasal administration. } \\
\hline \multicolumn{5}{|c|}{$\begin{array}{l}\dagger \text { Includes 'speed' (the powder form, rather than the generic term applied to all forms of amphetamine/methamphetamine), base (aka } \\
\text { 'pure'), ice (aka 'crystal', 'shabu') and liquid methamphetamine ('oxblood'). }\end{array}$} \\
\hline
\end{tabular}


range 2-13 years). Although not strictly comparable, only 5 per cent of the general population are unemployed at any one time (this figure does not include those on income support). ${ }^{10}$

\section{Recent drug use}

Recent use refers to use on at least one occasion in the six months preceding the participant's interview. As has been demonstrated elsewhere, polydrug use is the norm among Australian IDU, and high rates of polydrug use were observed in this sample (Table 2). Full results of recent drug use patterns by the 2004 national sample are reported elsewhere. ${ }^{9}$

\section{Self-reported aggressive behaviour}

Overall, 28 per cent of participants reported becoming verbally aggressive following use of alcohol and/or another drug in the six months preceding their interview (Figure 1). A smaller proportion (15 per cent) reported becoming physically aggressive following substance use in the preceding six months. There were no significant gender differences. The most commonly reported drugs after which aggression occurred were alcohol, methamphetamine (particularly ice/crystal), benzodiazepines and heroin.

Logistic regressions were conducted to determine predictors of verbal and physical self-reported substancerelated aggression. Variables that were significant at the univariate level were included in the model; these were drug of choice, age, arrest within the past year and selfreported crime in the past month. Participants reporting methamphetamine (including ice/crystal) as their drug of choice were significantly more likely to report becoming verbally and physically aggressive than those reporting

\section{BOX 1}

POLICIES FOR HEALTH SERVICES TO HELP MANAGE POTENTIAL AGGRESSIVE BEHAVIOUR AMONG THE INJECTING DRUG USER POPULATION

- The development and regular review of management strategies for staff and client safety

- Improving the competence and safety of staff working with clients or users who may be prone to aggressive behaviour. This may include training for dealing with difficult clients, increasing awareness of security protocols for staff, and improving co-operative links between mental health, law enforcement and drug service personnel.

- $\quad$ Providing anger management and assertiveness training to health service clients, particularly younger users.

- Providing staff training in the identification, management and/or treatment of individuals with signs of amphetamine psychosis. preference for another drug (Table 3).

Age was also significantly associated with substance-related physical aggression, with younger IDU (under 25 years of age) more likely to report becoming physically aggressive following use of a drug than those aged 25 and over (Table 3 ). This was not due to heavier methamphetamine use in this group. There was no association between particular age groups and self-reported verbal aggression.

\section{Criminal activity}

Participants reporting a prison history (46 per cent of the sample) were no more or less likely to report substancerelated aggressive behaviour towards another person. Those who reported having been arrested in the preceding 12 months (42 per cent of the sample), however, were more likely to report having become verbally and/or physically aggressive following drug use (Table 3 ).

Those IDU who reported committing a crime in the preceding month (49 per cent, $n=453$ ) also reported significantly higher levels of aggression than those who did not report recent criminal activity (Table 3 ).

\section{DISCUSSION}

Although collection of more specific information surrounding the frequency, occasions, situations and contexts in which aggression occurred was beyond the scope of the current project, these findings confirm anecdotal reports suggesting that injecting drug users both experience and are subject to substantial levels of substance-related aggression. Consistent with previous research, three of the four most commonly reported drugs preceding aggressive behaviour were alcohol, methamphetamine (particularly ice/crystal) and benzodiazepines.

It may seem surprising that heroin, a depressant not known for its aggression-inducing qualities, was also commonly nominated as being linked to aggressive behaviour. This may be due partly to the high rates of heroin use among the sample as a whole. It is also likely, however, that results may reflect behaviors during withdrawal from heroin-for example being more prone to aggression when feeling unwell, and/or engaging in aggressive behaviour to obtain the drug - rather than its direct effects per se. This will be investigated in more detail in the 2005 IDRS (forthcoming).

Participants with a preference for methamphetamine were more likely to report becoming verbally and physically aggressive following use of a drug than participants nominating another substance (typically heroin) as their drug of choice. As methamphetamine is increasing in availability in NSW, police and health agencies may see an increase in methamphetamine-related aggression or violence. This has implications for treatment services, given that half of the current sample were engaged in treatment (mainly opioid pharmacotherapy). Box 1 contains a list of measures that could assist health and other sectors 
who regularly interact with this population to manage the potential for aggressive behaviour.

Younger IDU were more likely to report physically aggressive behaviour than were their older counterparts. IDU who had been arrested in the past year were also more likely to report substance-related aggression, as were IDU who reported committing a crime in the month preceding interview. This suggests that aggressive individuals may be more likely to come to the attention of police and have greater involvement with law enforcement and related agencies such as the Magistrates Early Referral Into Treatment program (MERIT) and Drug Courts.

These findings suggest that for a proportion of IDU, but not all, there is a link between substance use and aggressive behaviour. Unfortunately it was not possible to assess this association over time as survey items concerning substance-related aggression were first included in the IDRS questionnaire in 2004. Within this sample, it did appear that methamphetamine was attributed by IDU as being one of the drugs most commonly linked to aggressive behaviour-this was particularly true of ice/crystal.

Some drug users may be more likely to come to the attention of police because of a combination of individual predisposition and the effects of drug use. This finding suggests the importance of improving the awareness and knowledge of where to seek help among substance users, and developing harm reduction messages around methamphetamine use, such as having rest breaks between occasions of use.

While aggression may be an important issue in relation to methamphetamine use, this should not detract attention from other substances identified as related to aggression, for example alcohol, heroin and benzodiazepines. Further, the context within which substance-related aggressive incidents occur should also be considered, as previous research (and common sense) suggests that a combination of factors in addition to substance use may mediate aggressive behaviour, and might be usefully considered in future work.

\section{ACKNOWLEDGEMENTS}

The Illicit Drug Reporting System is funded by the Australian Government Department of Health and Ageing and the National Drug Law Enforcement Research Fund. The National Drug and Alcohol Research Centre is funded by the Australian Government Department of Health and Ageing. We thank the agencies and individuals who assisted with recruitment and interviewing of IDU. Finally, we thank the IDU who were willing to be interviewed and share their experience.

\section{REFERENCES}

1. Topp L, Degenhardt L, Kaye S, Darke S. The emergence of potent forms of methamphetamine in Sydney, Australia. A case study of the IDRS as a strategic early warning system. Drug Alcohol Rev 2002; 21: 341-8.

2. Boles SM, Miotto K. Substance abuse and violence: A review of the literature. Aggress Violent Beh 2003; 8: 155-74.

3. Hoaken PNS, Stewart SH Drugs of abuse and the elicitation of human aggressive behavior. Addict Behav 2003; 28: 1533-54.

4. Wright S, Klee H. Violent Crime, aggression and amphetamine: what are the implications for drug treatment services? DrugEduc Prev Polic 2001; 8: 70-90.

5. Henry-Edwards S. The relationship between amphetamines and violence. In: Making a world of difference. An international focus on reducing problems from alcohol, tobacco and other drug use. Proceedings of Australia's $1^{\text {st }}$ international alcohol, tobacco and other drugs nursing and midwifery conference. Adelaide, South Australia, 2003.

6. Giancola PR. Individual difference and contextual factors contributing to the alcohol-aggression relation. Diverse populations, diverse methodologies: An introduction to the special issue. Aggressive Behav 2003; 29: 285-7.

7. Lynam DR, Leukefeld C, Clayton RR. The contribution of personality to the overlap between antisocial behavior and substance use/misuse. Aggressive Behav 2003; 29: 316-31.

8. Paton C. Benzodiazepines and disinhibition: A review. Psychiatric Bulletin 2002; 26(12): 460-2.

9. Stafford J, Degenhardt L, Black E. Australian drug trends 2004: Findings from the Illicit Drug Reporting System (IDRS). Drug Trends Bulletin. October 2004. Sydney: National Drug and Alcohol Research Centre, University of New South Wales; 2005.

10. Australian Bureau Of Statistics. Labour force Australia. Cat. No 6202.0. Canberra: Australian Bureau of Statistics; 2005. 종 